\title{
LITERATURA E CAMINHADA: PROBLEMAS DE MEDIAÇÁO DE LEITURA
}

\section{LITERATURE AND WALKING: READING MEDIATION QUESTIONS}

\author{
Demétrio Alves Paz \\ Universidade Federal da Fronteira Sul, UFFS, Campus Cerro Largo, RS, Brasil \\ Saulo Gomes Thimóteo \\ Universidade Federal da Fronteira Sul, UFFS, Campus Realeza, PR, Brasil \\ Pablo Lemos Berned \\ Universidade Federal da Fronteira Sul, UFFS, Campus Cerro Largo, RS, Brasil
}

\begin{abstract}
Resumo: Este texto propõe-se a discutir a importância da mediação no processo de formação de leitores no ambiente escolar e os benefícios que podem derivar do hábito da leitura. Nesta perspectiva, cabe ao professor um papel fundamental de promover o acesso às mais variadas expressôes da literatura às novas geraçôes e fomentar um debate permanente na sala de aula a partir da prática da leitura compartilhada. A valorizaçấo da leitura oferece a descoberta e redescoberta de textos em que cada leitor pode se apropriar e moldar o modo de perceber a si mesmo e ao mundo em sua volta.
\end{abstract}

Palavras-chave: Ensino de literatura; Mediador de leitura; Leitura em sala de aula.

Abstract: This essay discusses the importance of mediation in the reading formation process in primary and secondary school and the benefits that can derive from the reading habit. In this perspective, the teacher has a fundamental role to promote the access to different literary expressions to new generations and encourage a permanent debate in the classroom by the practice of reading share. The valorization of reading offers the discovery and rediscovery of texts in which each reader can appropriate and form a way of perceiving oneself and the world around him or her.

Keywords: Literature teaching; Reading mediator; Classroom reading.

Quando Lúcia Peláez era pequena, leu um romance escondida. Leu aos pedaços, noite após noite, ocultando o livro debaixo do travesseiro. Lúcia tinha roubado o romance da biblioteca de cedro onde seu tio guardava os livros preferidos.

Muito caminhou Lúcia, enquanto passavam-se os anos. Na busca de fantasmas caminhou pelos rochedos sobre o rio Antióquia, e na busca de gente caminhou pelas ruas das cidades violentas. 
Muito caminhou Lúcia, e ao longo de seu caminhar ia sempre acompanhada pelos ecos daquelas vozes distantes que ela tinha escutadocom seus olhos, na infância.

Lúcia não tornou a ler aquele livro. Não o reconheceria mais. O livro cresceu tanto dentro dela que agora é outro, agora é dela. (GALEANO, 1991, p. 20).

Lúcia, a personagem de um texto de Eduardo Galeano (1991) intitulado $A$ função do leitor/1, realizou, enquanto leitora, a junção mais profícua que poderia: apoderar-se da obra, de tal modo que ambas se transformaram no contato mútuo. Na metáfora do "caminhar", em que se confundem a vida e as leituras realizadas ao longo do tempo, as buscas e as descobertas de Lúcia revelam a sensibilidade tanto para a fantasia quanto para as contradiçóes sociais. Com isso, Galeano nos induz a perceber que o arcabouço de leituras de Lúcia, originado no prazer do ato de ler cercado de mistérios, não apenas fazem dela quem ela é, mas que os livros são lidos e significados pelos leitores em um exercício que é íntimo de cada um.

Além disso, o livro lido e apropriado por Lúcia é aquele que o leitor do texto de Galeano também tem como seu, pois o fato de não nomear a obra deflagra nele essa associação. O caráter de sugestáo do texto implica a cada um de nós associar a leitura de Lúcia às nossas próprias leituras, propiciando um processo de empatia pela personagem. Sobre esse aspecto, Harold Bloom provoca-nos:

Exorto o leitor a procurar algo que lhe diga respeito e que possa servir de base à avaliação, à reflexão. Leia plenamente, não para acreditar, nem para concordar, tampouco para refutar, mas para buscar empatia com a natureza que escreve e lê (BLOOM, 2001, p. 25).

Portanto, a empatia só surge quando nos abrimos ao outro, ao desconhecido, ao conhecimento do próximo. Assim inicia-se o contato com obras literárias. Consideremos, contudo, que ainda há dois outros elementos extremamente importantes na história: o tio e a biblioteca. Qual foi o papel do tio? Ter e disponibilizar, deixando ao alcance da jovem, uma biblioteca não só bonita - ela é feita de cedro - como também uma seleção pessoal das obras estimadas. Alguém disponibilizando, mostrando, guiando o leitor em potencial (e todas as pessoas são leitores em potencial), basta ter quem o incentive ou oriente.

Esse estímulo à leitura coloca-se como fundamental no processo de formaçáo de leitores. No conto $O$ menino que escrevia versos, do escritor moçambicano Mia Couto (2009), um médico, diante da família avessa à 
manifestação literária que o filho demonstrava, consegue auxiliar o jovem escritor, dando-lhe livros para poder se encontrar nos caminhos das palavras. Nessa perspectiva, nosso objetivo consiste em discutir o papel que o professor tem como agente mediador de leitura não só em sala de aula, mas também para além dela, principalmente pelo exemplo. Pautamo-nos em nossa experiência como professores de Literatura do curso de Letras da Universidade Federal da Fronteira Sul (UFFS), coordenadores de programas de iniciação à docência, tais como o PIBID e o Residência Pedagógica, coordenadores de projetos de pesquisa, ministrantes de cursos de extensão voltados à formação continuada de professores e de nossa experiência anterior como docentes na Educação Básica.

\section{Leitura: o leitor e a escrita da cultura}

Entre leitores, a pergunta sobre a importância ou a função da literatura pode, eventualmente, soar estranha. Por que se lê? A leitura literária na maioria das vezes não está atrelada a um objetivo pragmático. Lemos por prazer, por curiosidade, por distração... Porém, dada as condiçóes sociais e históricas de nosso tempo, de enaltecimento da utilidade de um saber "técnico" em detrimento do conhecimento artístico, faz-se necessário, pelos mais variados motivos, justificar o valor da literatura. Para compartilhar essa importância atribuída às mais variadas expressôes culturais que moldam a percepçáo dos homens sobre si e sobre o mundo a sua volta, recorremos a vários escritores e teóricos que possuem a mesma preocupaçáo que nós; dentre eles, Michèle Petit (2009) nos elucida:

\footnotetext{
Mitos, contos, lendas, poesias, peças de teatro, romances que retratam as paixóes humanas, os desejos e os medos ensinam às crianças, aos adolescentes, aos adultos também, não pelo raciocínio, mas por meio de uma decifração inconsciente, que aquilo que os assusta pertence a todos. Sáo tantas as pontes lançadas entre o eu e os outros, tantos os vínculos entre a parte indizível de cada um e a que é mostrada aos outros (PETIT, 2009, p. 116).
}

A antropóloga francesa, especialista em leitura, com vasta experiência também na América Latina, percebeu e mostrou de que forma diferentes vínculos são formados pela leitura. Seu trabalho reafirma a conclusão de que todos os gêneros sáo importantes e conquistam leitores de diferentes faixas etárias. Ao longo dos séculos e em variados contextos, as relaçóes humanas são encenadas e reencenadas pelas mais diversas possibilidades por artistas, 
de modo que temos acesso em qualquer biblioteca ou mesmo pela internet a uma vastidáo de bens culturais. $\mathrm{O}$ contato pessoal do leitor com parte desse repertório, ao propiciar uma reflexão sobre si mesmo ou sobre o mundo, pode vir a despertar o interesse pela leitura. A literatura, nesta perspectiva, serve como uma espécie de antena, que capta o mundo sensível circundante do leitor. Visão semelhante é expressa por Milan Kundera (2009):

[...] se a cultura europeia me parece hoje ameaçada, se ela está ameaçada do exterior e do interior naquilo que ela tem de mais precioso, seu respeito pelo indivíduo, respeito pelo seu pensamento original e pelo seu direito a uma vida particular inviolável, então, parece-me, essa essência preciosa do espírito europeu está depositada como uma caixa de prata na história do romance, na sabedoria do romance (KUNDERA, 2009, p. 152).

Kundera, ao abordar especificamente o romance, gênero que o consagrou como escritor, trata de todo texto literário, pois a representação (a mimesis aristotélica) é parte constituinte e fundamental da literatura. Os diferentes indivíduos que já foram apresentados e representados são tantos que é quase improvável não se enxergar em algum deles.

A sabedoria decorrente da prática em ler não é mensurável, pois se constitui aos poucos, leitura após leitura, assim como o amadurecimento do leitor. Raramente torna-se leitor da noite para o dia ou inicia-se leitor com obras canônicas. O leitor ouviu muitas histórias, foi instigado, desafiado, muito provavelmente cooptado por outro leitor. Assim, faz-se a cadeia de leitura. Um leitor ajuda na formação de outro leitor. Um livro indica outro livro, tal como Italo Calvino (2007) já propôs em seu texto Por que ler os clássicos?. Por entre uma série de tópicos de definição e discussão, o escritor italiano contrapóe dois deles: “4) Toda releitura de um clássico é uma leitura de descoberta como a primeira; 5) Toda primeira leitura de um clássico é na realidade uma releitura" (CALVINO, 2007, p. 11). Ambos os tópicos se presentificam na prática de sala de aula.

Quando o professor leva um texto clássico, como por exemplo um conto de Machado de Assis, um poema de Gregório de Matos ou uma peça teatral de Gil Vicente, ele já realizou a leitura prévia e organizou possíveis linhas de discussáo e análise. Mas, no decorrer da aula, os alunos sugerem uma interpretação, diferente da proposta, que também se alinha ao texto. Isso acontece, pois uma obra clássica parece nunca se encerrar, admitindo múltiplas leituras e abrindo-se a novos olhares, para a descoberta de novos sentidos sugeridos. 
Da mesma forma, os clássicos se mantêm perenes e atuais devido, em primeiro lugar, à sua inserção na cultura geral, por isso se podendo considerar que um clássico que se vai ler pela primeira vez sempre parece ser "relido". Nomes como Dom Quixote, Hamlet, Capitu e Diadorim, assim como versos como "E agora, José?", "Amor é fogo que arde sem se ver" e "Tudo vale a pena se a alma não é pequena" são evocados por diversos discursos, em incontáveis situaçóes, fazendo com que, quando o leitor tem contato com os livros de origem, é como se revisitasse algo já conhecido. Em segundo lugar, o escritor clássico canaliza e produz um enunciado que sintetiza a essência do ser humano e de seu eterno conflito de estar no mundo, fazendo com que desperte em cada leitor um conhecimento que ele mesmo possuía, mas ainda em modo abstrato, e que se concretiza quando lê aquela sequência de palavras que formam um texto.

Paralelamente aos clássicos, um dos caminhos para a formação de leitores é o uso da literatura contemporânea, tal como já fizemos em cursos de extensão e formação continuada, em nossa prática no PIBID e PRP, em projetos de pesquisa e em sala de aula com alunos da graduaçáo em Letras. Ao mesmo tempo em que a formação dos professores de línguas e literaturas exige a familiarizaçáo com textos da tradição literária ou resgatados do apagamento histórico, o contato com textos contemporâneos póe o leitor em contato com temas e formas de representaçáo do sujeito contemporâneo, em seus dilemas, perspectivas e contradiçôes. Ler a literatura produzida nas últimas décadas é também contrapor-se a uma perspectiva que concebe como arte apenas as obras já consagradas pela crítica, portanto restrito ao passado e, logo, cristalizado. Ainda tratando da contemporaneidade, o prêmio Nobel de Literatura do ano de 2010, Mário Vargas Llosa (2002), nos diz:

\footnotetext{
Em vez de se deprimir ou se considerar um ser obsoleto, expulso da modernidade, o escritor do nosso tempo deve, isso sim, sentir-se estimulado pelo formidável desafio que significa criar uma literatura que seja digna daquela, capaz de chegar a esse imenso público potencial que o espera, agora que, graças à democracia e ao mercado, existem tantos seres humanos que sabem ler e podem comprar livros, coisa que jamais aconteceu no passado[...] (LLOSA, 2002, p. 77).
}

Vivemos na era da disponibilidade da informação. Ela está presente em diferentes suportes e muito acessível, o que até entâo na história da humanidade nunca tinha acontecido. Há um mercado que dita certas regras para as vendas, mas há também um público leitor que foge desse "mercado" literário, assim como produtores culturais que igualmente promovem uma 
experiência diferenciada com o texto literário. Há feiras, festas, congressos, concursos e premiaçóes que incentivam a criatividade e a diversidade, assim como a democratização ao acesso à literatura, porque os textos literários servem não só como entretenimento, mas também como uma maneira de apreendermos mais sobre nós e os outros, que nos antecederam, que são contemporâneos em diferentes lugares. A escritora canadense, Nancy Huston, propóe uma possível resposta:

\begin{abstract}
Apresentando-se como uma ficção, nos dando a oportunidade de escolhêla, a literatura nos libera, por um tempo, das obrigaçóes e das pressôes das inúmeras ficçôes a que somos submetidos. Ela nos dá de presente uma realidade que, embora mais reconhecível, é diferente: mais precisa, mais profunda, mais intensa, mais plena, mais durável do que a realidade do lado de fora. No melhor dos casos, ela nos dá forças para retornar a esta realidade aqui e lê-la, também, com mais perspicácia [...] (HUSTON, 2010, p. 133).
\end{abstract}

Percebemos, portanto, que o contato com a literatura nos oferece a experiência de acompanharmos outros ambientes, outras personagens, outras formas de pensar sobre e agir no mundo e, por consequência, aprendemos a questionar discursos que se apresentem como limitantes ou unilaterais. Ainda que a leitura de textos literários não se proponha a transmitir conhecimentos objetivos, podemos aprender muito ao ler, pois o hábito nos emancipa intelectualmente e nos auxilia a ler a realidade. Fahrenheit 451 (BRADBURY, 2009), uma obra sobre a perseguição/criminalização da leitura numa sociedade futura, mas também um elogio aos leitores, "os homens livros", destaca o valor de textos literários:

A magia está apenas no que os livros dizem, no modo como confeccionavam um traje para nós, a partir de retalhos do universo. [...] você sabe por que livros como este sáo importantes? Porque têm qualidade. E o que significa a palavra qualidade? Para mim significa textura. Este livro tem poros. Tem feiçôes. Este livro poderia passar pelo microscópio. Você encontraria vida sob a lâmina, emanando em profusão infinita. (BRADBURY, 2009, p.121).

Dentre os vários benefícios possíveis da leitura, destacamos essa capacidade de ampliaçáo das diferentes visóes de mundo que são apresentadas aos leitores por meio dos textos literários. Uma das tarefas do professor, enquanto mediador de leitura, deve ser contribuir nessa ampliação. Dessa forma, cremos que a leitura de obras literárias aproxima leitores, visto que há o gosto pelo diálogo e pela troca de experiências, através de comentários 
sobre obras, personagens preferidos, autores lidos e recomendação de títulos. Tudo isso nos tira da rotina e nos faz pensar de forma independente.

\title{
Leitura mediada: Preparando o percurso
}

No contexto atual, a maior parte da população acaba tendo um contato mais aprofundado com a literatura, seja clássica, seja contemporânea, apenas no ambiente escolar, e projeta uma referência de leitor na figura do docente. Tanto nas aulas de língua materna e estrangeira, como nas de literatura, portanto, devemos, enquanto professores, recuperar a leitura de textos com valor estético, respeitando o desenvolvimento linguístico e cognitivo dos alunos. Da mesma forma, é uma obrigaçáo apresentar-lhes textos em que haja densidade semântica, originalidade no uso da língua, inovaçōes na forma, assim como diferentes visóes de mundo representadas nos textos. Portanto,

\begin{abstract}
Se ao estudante de hoje ensinarmos que o texto literário é não só um exercício da imaginaçấo artística mas também, em muitos casos, uma nova forma de ver o mundo que pode constituir em si mesma um ensinamento novo, pelo exemplo extraordinário das personagens ou pela expressão cuidada e original da escrita, entấo teremos inaugurado uma nova didática. (CEIA, 2002, p. 53).
\end{abstract}

Uma nova didática, contudo, não se resume a uma nova maneira de apresentar o texto, usando internet, filmes, músicas e outros suportes, mas pressupóe um jeito diferente de encarar o texto literário: como algo táo importante quanto os outros discursos que circulam. A literatura é mais livre tanto pela forma que pode adquirir quanto pelo modo de apresentar um conteúdo. Para Yolanda Reyes (2012, p. 28-29),

Um professor de leitura é, simplesmente, uma voz que conta; uma mão que abre portas e traça caminhos entre a alma dos textos e a alma dos leitores. E para fazer seu trabalho não deve esquecer que, para além de professor, é também um ser humano, com zonas de luz e sombra, com uma vida secreta e uma casa de palavras que têm sua própria história.

Seguindo os dois conselhos anteriormente citados estaremos contribuindo não só para a formação de leitores de textos literários, mas de cidadáos críticos, capazes de pensarem no outro, de colocarem-se no 
lugar do outro, de compreender angústias, inquietaçôes, sonhos, desejos, aspiraçôes. Enfim, de um ser humano consciente tanto de suas limitaçóes quanto do mundo circundante.

O papel do professor não pode se resumir a indicar um livro, um texto a ser lido. Ele tem de apresentar a obra, de acompanhar a leitura, guiar, tirar dúvidas, propor novas questóes para o leitor adquirir autonomia e compreensão de que há diferentes leituras para um texto, não uma só e irredutível. Também é função dele incluir leituras novas (contemporâneas) e diversificadas (diferentes gêneros), discutir os sentidos expressos no texto, estimular o desenvolvimento de argumentos para debater valores e gostos. Trazer para o debate em aula questôes como: o que é, afinal, uma boa obra? $\mathrm{O}$ que transforma um texto em bom? O que diferentes leitores (na sala de aula, na escola) notaram naquele texto?

Conforme Thomas C. Foster (2010) aponta, no livro Para ler literatura como um professor, três são as palavras fundamentais para o leitor em profundidade: "Memória. Símbolo. Padrão." (FOSTER, 2010, p. 15). A memória é a noção de que todo texto literário e filmes, músicas e séries fazem parte de uma única história, o arquivo comum da cultura da humanidade, com cada novo texto acrescentando algo, ao mesmo tempo em que ecoa e evoca associaçóes com textos passados. Todas essas conexóes possíveis se produzem graças aos símbolos. Os professores exercitam justamente essa leitura simbólica, que se pode aplicar a cada personagem, açáo, cena ou temática desenvolvidas pelos escritores. Por fim, o padráo é a investigação das estruturas utilizadas pelos escritores em suas obras. Em uma leitura inicial, pautada pelo afeto e reconhecimento, tais palavras fundamentais não estáo de todo envolvidas, mas, num segundo nível, passase a compreender o enredo e os detalhes de um modo muito mais analítico.

Nesse sentido, cabe ao professor explorar esses sentidos que se escondem por detrás das linhas escritas. De modo semelhante ao papel desempenhado pela figura paterna, em outro texto de Eduardo Galeano (1991), intitulado $A$ função da arte/1:

Diego não conhecia o mar. O pai, Santiago Kovadloff, levou-o para que descobrisse o mar. Viajaram para o sul. Ele, o mar, estava do outro lado das dunas altas, esperando. Quando o menino e o pai enfim alcançaram aquelas alturas de areia, depois de muito caminhar, o mar estava na frente de seus olhos. E foi tanta imensidão do mar, e tanto seu fulgor, que o menino ficou mudo de beleza. E quando finalmente conseguiu falar, tremendo, gaguejando, pediu ao pai: “- Me ajuda a olhar!” (GALEANO, 1991, p. 15). 
Associando essa história à função do professor, a descoberta da literatura, como a descoberta do mar pelo menino, náo pode ser feita por outra pessoa senão por ele. $\mathrm{O}$ adulto não deve impor a sua visão (pois isso pode se tornar uma experiência traumática), como também não deve deixar a criança à própria sorte, pois é "tanta imensidáo", na literatura e no mar, que os neófitos facilmente se perdem no que veem. Por isso Diego pede ajuda para olhar, para que o pai o guie, nas dificuldades e deslumbramentos que podem surgir e sempre apresentar novos modos de enxergar.

Voltando ao ambiente escolar, deve-se ter em mente que a escola é, a princípio, o início da inserção de jovens na tradição leitora ocidental. Ao introduzi-los nesse novo universo, faz-se necessário o professor acompanhar com mão firme e acolhedora, apresentando diversidade não só de textos, mas também de visões. Na diversidade, mostrar textos clássicos, já consagrados, e textos novos, jovens, contemporâneos, com ou sem respaldo da crítica especializada. Aliás, questionar o cânone, incluindo representatividade: de mulheres, negros, indígenas, homossexuais. Afinal, todos têm o que contar, o que dizer a respeito de si e da sua forma de perceber o mundo.-

\section{Leitura em sala de aula: caminhando junto}

A sala de aula coloca-se como um espaço privilegiado para a realizaçáo da mediação de leitura, visando a formação de leitores. É nesse espaço, em que professor e a turma exercem a cumplicidade necessária para exporem suas ideias, onde é permitido errar, debater e reconsiderar as percepçóes individuais coletivamente, que a leitura e a discussão sobre a obra lida podem conquistar o interesse pela literatura. Proporcionar momentos de encontro com essa magia é uma das funçóes que a escola deve proporcionar. A biblioteca é um espaço para o contato com os livros, principalmente por ser onde eles estão armazenados, mas não é o único. O primeiro e principal local para o manuseio e a leitura de obras é a sala de aula.

De certa forma, a sala de aula é um lugar enigmático, pois é a reuniáo de um grupo heterogêneo com uma função homogênea, apesar de todos terem diferentes propósitos ali. Durante muito tempo, qualquer atividade alternativa (ler textos não contidos no livro didático, assistir filmes, ouvir músicas, visitas ao teatro ou museus) era vista como uma aula "perdida" ou "sem conteúdo". A docência restringia-se ao uso do espaço físico da sala de aula e do uso do quadro negro e do livro didático. Acreditamos que o estudante deve reconhecer a sala de aula como um espaço seu, um local 
agradável, não só de convivência social mas principalmente de aprendizado. Paulo Coimbra Guedes e Jane Mari de Souza (1998, p. 22-23) possuem uma resposta interessante para a questáo:

A sala de aula é o lugar onde o professor ensina, onde ele mostra, por sua presença e sua atuação, a importância da leitura: ele traz os livros, apresentaos, quer que todos escolham o que vão ler, fica sabendo do interesse que se vai formando em cada um, faz sugestôes, discute, aprofunda os assuntos, responde perguntas e lê com seus alunos.

Uma possível e não muito difícil solução, a partir do apresentado anteriormente, é transformar a sala de aula em um local de debate permanente, por meio da leitura, sobre o mundo circundante. Michèle Petit enfatiza que: "Os espaços coletivos de leitura tiram cada um de sua solidão, fazem-no compreender que esses tormentos sáo compartilhados pelos que estão a seu lado, mas também por aqueles que encontram nas páginas lidas ou por quem as escreveu." (PETIT, 2009, p. 165). Assim, construir esses espaços é mais do que uma necessidade, é uma urgência. Contudo, para que a prática de leitura em aula seja acolhedora às diferentes percepçóes dos alunos e valorize o exercício do diálogo e da argumentaçáo, é essencial uma descentralização da figura do professor como fonte absoluta do saber para uma postura de mediaçáo, como aponta a escritora argentina, Cecilia Bajour (2012, p. 68):

Um dos procedimentos fundamentais para que os leitores aprendam a discutir sobre literatura é a garantia de que suas intervençóes sejam levadas em conta e de que o professor que coordena a conversa não seja o depositário de nenhuma verdade nem saber absoluto sobre os textos escolhidos. Quando o professor recorre ao próprio texto para que seja ele a responder às novas perguntas ou, mesmo que as deixe em aberto, estará indicando aos leitores o caminho para que consolidem sua argumentação a partir da materialidade do que as palavras e as ilustraçóes dizem ou calam.

O professor que fomenta o debate, conduzindo-o de forma a estabelecer uma comunidade de leitores, é alguém preparado com as ferramentas ideais: o livro e a mente aberta a diferentes leituras do mesmo texto, desde que o próprio texto as permita. Pois o texto literário, pelo seu caráter polissêmico e pelo predomínio de sua condição não-pragmática, apresenta-se às práticas escolares como um mecanismo potencialmente infinito de produçáo de sentidos. Os textos carregam temas dos mais diversos, conhecimentos, 
situações que, de forma ou outra, os leitores podem ser confrontados a projetarem sua própria experiência, visão de mundo, sonhos e referências de outras leituras identificando-se e, como Lúcia, apropriando-se da leitura feita.

Acontece, porém, algumas vezes, de a escola acabar desincentivando a leitura. Infelizmente, diante dos discursos que privilegiam uma concepção muito restrita de literatura, muitos professores julgam que há leituras melhores do que as outras porque foram ensinados assim. Nessa perspectiva, há um cânone que se apresenta como estabelecido e intocável, ao qual não há o que questionar, nem o que incluir. $\mathrm{O}$ que muitos desses docentes esquecem é que:

O leitor não profissional [...] lê essas obras não para melhor dominar um método de ensino, tampouco para reiterar informaçốes sobre as sociedades a partir das quais forma criadas, mas para nelas encontrar um sentido que lhe permita compreender melhor o homem e o mundo, para nelas descobrir uma beleza que enriqueça sua existência; ao fazê-lo, ele compreende melhor a si mesmo. O conhecimento da literatura náo é um fim em si, mas uma das vias régias que conduzem à realização pessoal de cada um (TODOROV, 2009, p.32).

Ao compreender, de fato, o ensinamento de Todorov, o professor pode guiar melhor os seus leitores em potencial. Por que não trazer Harry Potter, Percy Jackson e outros para a sala de aula e mostrar os elementos das "grandes" obras que estão ali? Como não comparar Percy Jackson com a Ilíada e a Odisseia, assim como trazer a tragédia grega para a sala de aula? Por que não comparar a história de amor de Bella e Edward (da série Crepúsculo) com os grandes pares da cultura ocidental? Além de Heathcliff e Catherine, de Morro dos ventos uivantes, citados pelos vampiros de Stephenie Meyer, tem-se Príamo e Tisbe, de Metamorfoses, Tristáo e Isolda, do romance medieval de mesmo nome, Dante e Beatriz, presentes na Divina Comédia, Romeu e Julieta, da peça homônima de William Shakespeare, e tantos outros casais apaixonados existentes. A aula de literatura pode (na verdade, deve) ser o local de referenciar, de mostrar, de incentivar e conduzir os leitores nessa longa jornada livro adentro.

Heloísa Seixas (2011) relaciona a liberdade de ler à liberdade de pensar, mas lamenta que muitos não gostem de ler. Afinal, a leitura demanda, para além da alfabetização, a concentração e o silêncio, que se opóem ao frenético modelo de vida imposto pela sociedade do espetáculo e 
do consumo. O cultivo ao hábito de leitura, pelos valores sociais imediatistas que têm orientado inclusive as reformas educacionais (voltadas para "escolas técnicas", "preparação para o trabalho", "empreendedorismo", etc.), parece por vezes um entrave à uma visão (bastante restrita) de progresso. Porém, o grande problema das pessoas que náo gostam de ler é ter de acreditar no que ouvem. Nancy Huston alerta para o fato que:

\begin{abstract}
Quanto mais uma pessoa se acha realista, mais ela ignora ou rejeita a literatura como um luxo ao qual não tem direito, ou como distraçáo para a qual não tem tempo, e mais essa pessoa tem chances de cair no Arquetexto, ou seja, na veemência, na violência, na criminalidade, na opressão do próximo, das mulheres, dos fracos ou até de um povo inteiro (HUSTON, 2010, p. 128).
\end{abstract}

Vista dessa forma, a literatura transforma-se em algo que está fora do alcance de grande parte da populaçáo. Entretanto, a falta de leitura leva aos extremos elencados pela escritora canadense. É mais fácil manipular um não leitor, pois argumentos que parecem bons ou coerentes facilmente convencem-no de que é o correto. Um leitor não se deixa influenciar tão levianamente.

Na pesquisa Retratos da leitura no Brasil (2020) alguns dados são dignos de nota. Os não leitores alegam não ler por falta de tempo. Será essa informação correta? Às vezes é muito mais uma não percepção de como o tempo se esvai em atividades outras. Usar as redes sociais, assistir televisão, ouvir música, embora sejam fontes de lazer que tendem mais à passividade do que a um envolvimento mais efetivo, podem ser substituídas, ao menos em parte, pela leitura de textos literários. Geralmente, associa-se à leitura de romances, como Senhora, Memórias póstumas de Brás Cubas, Grande Sertáo: Veredas ou A paixáo segundo G.H., que demandam, claro, tempo e atençáo. Essa visão projeta-se sobre o senso comum de que seria necessário uma espécie de ritual e isolamento para a leitura, justificativa frágil a que se escoram aqueles que não possuem um hábito de leitura. Um conto, uma crônica, um poema, inclusive podendo-se acessar tais textos pelo computador ou celular, é um bom ponto de partida aos ainda náo leitores, lidos em um espaço de tempo relativamente curto. Deve haver, sobretudo, a curiosidade, por parte do leitor, de abrir-se para o descobrir desses textos.

Infelizmente (e esta reflexão é mais do que necessária) a escola pode ser uma razão para haver não leitores. Muitas vezes a leitura torna-se apenas um meio de avaliaçáo: a famosa e temida prova de leitura. Anteriormente, 
tratamos do papel que todos desempenham na formação de leitores, mas os mesmos agentes podem desempenhar a função de não formar leitores.

No ensaio $O$ conto em língua portuguesa em sala de aula, são apresentados alguns números interessantes para pensar o quanto os não leitores não leram na escola. Ao dedicar um período (aula) por semana de Língua Portuguesa no Ensino Fundamental e um no Ensino Médio, haverá um volume considerável de leituras feitas na escola, sob a supervisão e seleção de um professor, qualificado para isso. Se o:

[...] aluno ler um poema por aula, um conto a cada duas, e um romance por mês. Em um ano teremos 40 poemas lidos, 20 contos e 10 romances. Essa é uma quantidade enorme de leitura, pois a média nacional é de 1,8 livros. Se aplicarmos o mesmo cálculo para todos os anos em que há Língua Portuguesa, se o professor destinar um período semanal para a leitura, no final da vida escolar, o número é impressionante. Se multiplicarmos por 7, os dados anteriores transformam-se em: 280 poemas, 140 contos e 70 romances. (PAZ, 2015, p. 274).

Mesmo com todos os problemas que há, os leitores ainda resistem e existem. Uns, são ávidos leitores de textos que não gozam de prestígio no ambiente escolar. Alguns ainda estâo em estado de letargia, esperando pelo momento certo para despertarem. Outros, infelizmente, talvez nunca tenham a oportunidade.

\section{Consideraçóes finais}

O mosaico de ideias, citações e reflexôes anteriormente apresentado teve por função contribuir com a crença de que a escola, com seus professores leitores, deve perseverar na formaçáo de leitores. Todos os tipos de textos têm de fazer parte do rol de leituras dos estudantes, porém a literatura tem um papel emancipador e crítico, livre, por meio da ficção, de se apresentar como um meio de apreensão da realidade que grande parte dos outros não tem. E valer-se da sala de aula como um local de leitura, portanto, ajudaria a mudar um pouco o número de não-leitores. Abrir as portas de um mundo novo proporciona vários benefícios, além dos que são habitualmente apresentados: aumentar vocabulário e escrever melhor.

Além disso, a pesquisa Retratos da leitura no Brasil (FAILLA, 2020) nos informa que os leitores ocupam seu tempo de forma diversificada. Participam de atividades culturais (cinema, teatro, shows, exposiçóes 
artísticas), praticam exercícios físicos, encontram-se com amigos. Dessa forma, a leitura enriquece o leitor tornando-o mais saudável, mais sociável, mais aberto a diferentes espaços e ambientes, assim como o liga a mais pessoas. Como Antonio Candido (2011) já disse há muito tempo: a literatura é um direito. A escola e o professor têm a tarefa de apresentar esse direito. Cabe ao leitor saber usufruí-lo.

\section{Referências}

BAJOUR, Cecília. Ouvir nas entrelinhas: o valor da escuta nas práticas de leitura. São Paulo: Pulo do gato, 2012.

BLOOM, Harold. Como e por que ler. Rio de Janeiro: Objetiva, 2001.

BRADBURY, Ray. Fahrenheit 451. São Paulo: Globo, 2009.

CALVINO, Italo. Por que ler os clássicos. São Paulo: Companhia das Letras, 2007.

CANDIDO, Antonio. Formaçáo da Literatura Brasileira. Belo Horizonte: Itatiaia, 1997. 2 Volumes.

CANDIDO, Antonio. O direito à literatura. In: CANDIDO, Antonio. Vários escritos. Rio de Janeiro: Ouro sobre Azul, 2011.

CEIA, Carlos. O que é ser professor de literatura. Lisboa: Edições Colibri, 2002.

COUTO, Mia. O fio das missangas. São Paulo: Companhia das Letras, 2009.

FAILLA, Zoara (coord.). Retratos da leitura no Brasil, 5. ed. 2020. Disponível em: https://www.prolivro.org.br/5a-edicao-de-retratos-da-leiturano-brasil-2/a-pesquisa-5a-edicao/

Acesso em: 23 dez. 2020.

FOSTER, Thomas C. Para ler literatura como um professor. São Paulo: Lua de Papel, 2010.

GALEANO, Eduardo. O livro dos abraços. Porto Alegre: L\&PM, 1991.

HUSTON, Nancy. A espécie fabuladora. Porto Alegre: L\&PM, 2010.

KUNDERA, Milan. A arte do romance. São Paulo Companhia das Letras, 2009.

LLOSA, Mario Vargas. A linguagem da paixão. São Paulo: ARX, 2002. 
GUEDES, Paulo Coimbra; SOUZA, Jane Mari de. Leitura e escrita são tarefas da escola e não só do professor de português. In: NEVES, Iara Conceição Bitencourt (et al.). Ler e escrever: compromisso de todas as áreas. Porto Alegre: Editora da UFRGS, 1998.

PAZ, Demétrio Alves. $O$ conto em língua portuguesa em sala de aula. Sáo Paulo, Via Atlântica, n. 28, p. 261-276, Dez/2015.

PETIT, Michèle. A arte de ler. São Paulo: Editora 34, 2009.

REYES, Yolanda. Ler e brincar, tecer e cantar. Literatura, escrita e educação. São Paulo: Pulo do gato, 2012.

SEIXAS, Heloísa. O prazer de ler. Rio de Janeiro: Casa das palavras, 2011. TODOROV, Tzvetan. A literatura em perigo. Rio de Janeiro: Difel, 2009. 